\title{
Fuzzy-interval modification of the earned value method in manufacturing digitalization project management
}

\author{
Daria Korenkova \\ Assistant of the department «Entrepreneurship and foreign economic activity» Bauman University, \\ Moscow
}

\begin{abstract}
The specifics of managing complex projects of digital transformation of the industry are considered, the problems of decision making in conditions of uncertainty, insufficient formalization and structuring of tasks are disclosed. A methodological approach to the fuzzyinterval assessment of the indicators of the mastered volume in the management of production digitalization projects is proposed. Directions for the implementation of the proposed approach in expert and recommendation systems are determined.
\end{abstract}

Keywords: manufacturing digitalization, decision making, project management, earned value method, fuzzy logic, fuzzy-interval estimation.

\section{Introduction}

The modern concept of the digital transformation of industry involves the creation of "digital doubles" of industrial products, the processes of their production and operation. In a single information space, modeling of development, design, production and post-production stages of the life cycle of complex technical products is carried out. This allows you to achieve a qualitatively new level of organization of production, radically transform existing and create new business models based on the principles of open innovation, open software, and hardware. The priority of digitalization is the algorithmization of simple operations, reducing the role of routine human labor and the formation of fully automated digital production processes using artificial intelligence technologies.

The digitalization of production project is a set of information and technological solutions for the formation of electronic models of production factors, the design of unified information systems and databases, the pairing of autonomous robotic systems, the modeling of contract activity and workflow, the automation of logistics and planning, the modernization of all systems product life cycle management, automation of the support process and management decision making. The complexity and capital intensity of production digitalization projects, the need to take into account many factors in the face of technical and economic risks determine the need for further improvement and development of the used management methods.

The main problem in making managerial decisions is the lack of effective tools for working in the face of uncertainty, insufficient formalization and structuring of tasks, 
instability of decisions and incompleteness of management information [1]. A problem of this kind is manifested in the assessment of the state and management of economic facilities at any level. This paper discusses the features of the micro-level in the management of projects, programs and project portfolios of digitalization of production. The development of methods for making sound economic decisions in a systematic analysis of the state and prospects of the project is an urgent task. Therefore, approaches and tools are needed that can perform soft calculations and operations on poorly organized information.

Among the areas of soft computing in the economic practice of project analysis can be identified: the principles of fuzzy logic and fuzzy decision-making; evolutionary and genetic programming approaches; swarm algorithms and other models of collective interaction of agents; network principles of analytics, including neural networks; approaches to the analysis of the environment of functioning and efficiency of complex systems. Artificial intelligence tools are relevant in applied economic problems project management due to the ability to work with non-strict, incomplete or distorted data.

\section{Methods and materials}

The standard method in project management for monitoring the status and status of a project is the Earned Value Management method [2]. It allows you to perform a detailed analytical review of key aspects of the project - the content, timing, and cost (budget). The main quantitative indicators of the method are the cost characteristics of the control parameters by the status of the project $[2,3]$ :

- Planned value (PV) - the planned cost of the proposed work, which must be completed in accordance with the project schedule by the specified key dates;

- Earned Value (EV) - the planned cost of the work performed in accordance with the project budget (the specified amount of work according to the project plan) actually fulfilled during the established project schedule;

- Actual Cost (AC) - the total actual cost of work performed during the established project schedule.

Further, the so-called derivatives of the characteristics of the mastered volume, representing the calculation of deviations and relations of planned and actual indicators. In this work, standard indicators are used for this assessment [2-4].

Using the described indicators, you can go to a graph-analytical study $[5,6]$ of the project status in the coordinates of the project status (timeline) and project budget (economic scale of maintenance and cost of work). It is possible to form a matrix of 4 quadrants [7-9].

Deadlines can be presented in a fuzzy-interval form [1], which significantly increases the validity of project planning due to the large proximity of the model to reality, in which there are uncertainty and unpredictable phenomena that affect the stability of too conservative and strict models of work.

Using the capabilities of the theory of fuzzy sets will allow reflecting objects with a different ratio of deviations in volume and terms on a familiar two-dimensional graph or square map, as well as assessing the degree of deviation and its various variations more generally due to interval estimates $[11,12]$.

The apparatus of fuzzy logic and fuzzy decision making is a generalized approach to the formalization of human mental activity and its algorithmization using interval, linguistic and categorical variables. The apparatus of fuzzy sets allows one to analytically present quality decisions of experts who describe objects of complex nature, with a large number of properties and parameters, ambiguous content, and other forms of uncertainty. The work of experts becomes more objective, systematic and flexible due to the fact that their judgments are not required to be precise and strict: the expert assessment is an interval with unclearly defined boundaries in the form of degree of reliability (degree of spread of values). Moreover, 
methods presented in non-clear-interval but quantitative form can be applied to analyze the sensitivity of the result to variations in the initial modeling parameters $[11,12]$, which is difficult to do with simple subjective estimates or classical probability formulas.

Expert and recommendation systems are based on work with the base of rules. Usually, they are based on the so-called "Production models", representing the group of designs "IFTO". Fuzzy expansion of the product model forms the basis of fuzzy rules. In this case, the fuzzy inference system for evaluating the results of project activities will formulate fuzzy linguistic statements in response to the operation of the rules for working with the values of input fuzzy variables $[11,12]$. When designing the base of fuzzy rules, the analyst must take into account the specifics of economic activity, industry characteristics of the tasks to be solved, as well as the individual characteristics of specific IT projects.

The problem of the work of traditional expert systems based on large bases of knowledge and rules is the manifestation of the ineffectiveness of working when the critical scale of the system is reached: there are too many rules for informed and prompt decision-making, contradictions and ambiguities accumulate when processing rules, it is too difficult to describe simple concepts natural logic using mathematical operations. Therefore, a reasonable solution is to use fuzzy expert and recommendation systems that can operate with a small base of fuzzy rules that can describe complex states and concepts from a natural human language $[11,12]$.

\section{Results}

The scientific objective of the study is to develop a toolkit for odd-to-interval estimation of the indicators of the mastered volume in the management of digitalization projects, ensuring the development of modern project management methodologies. Fuzzy-interval evaluation of projects uses the traditional project management apparatus, but expanded by the concepts of fuzzy logic. First of all, this refers to attempts to accurately regulate and strictly regulate the parameters of a complex project.

The first parameter, which requires fuzzification, is the deadlines for the project, since usually tasks and work are interconnected, and not always linearly. It is important to note that the methods of project management and monitoring of its status should be combined, and always have a tool for analyzing the temporary components of the project. Those. the use of the accumulated volume method should be supplemented by all known methods of calendar and network planning in order to receive a more objective and reasonable report on the real state of the project [13].

Thus, the modification is reduced to the following procedures:

1. The fuzzification operation is aimed at bringing the values of the indicators of the mastered volume under the project into the form of fuzzy membership functions that generalize real numbers to fuzzy intervals of assessments of the state of the project.

2. Coordination of fuzzy indicators is focused on the coordination of the results of obtained interval estimates of indicators of different nature, differences in expert opinions and incomplete initial information.

3. The operation of defuzzification and cognitive scientific visualization is aimed at the reverse transformation of the resulting fuzzy set into a specific point estimate in the form of clear numbers that can be represented in ergonomic form for decision-makers.

\section{Conclusion}

The proposed methodological approach to fuzzy-interval estimation of the acquired volume indicators in the management of production digitalization projects allows to take into account the high degree of uncertainty and risks specific to modern production digitalization 
projects. However, the directions of implementation of the proposed approach in expert and recommendation systems require mandatory clarification depending on the terms of research and allocated resources.

\section{References}

1. Ptuskin A.S. fuzzy models and methods in management. - Publishing house: Bauman Moscow State Technical University (Moscow), 2008, 215 p.

2. Fleming Q. W., Koppelman J. M. Earned value project management. Project Management Institute, 2016. 232 p.

3. Chen H. L., Chen W. T., Lin Y. L. Earned value project management: Improving the predictive power of planned value //International Journal of Project Management. 2016. V. 4. №. 1. P. 22-29.

4. Colin J., Vanhoucke M. A comparison of the performance of various project control methods using earned value management systems //Expert Systems with Applications. 2015. V. 42. №. 6. P. 3159-3175.

5. Shiboldenkov V.A. Instuments of neural network exploratory analysis of socio-economic processes // Audit and financial analysis. 2018. No. 6. p. 214-224.

6. Shiboldenkov V.A., Urazova E.I. A review of the cognitive tools of matrix visualization in making economic decisions // Scientific Review: theory and practice. 2018. No. 10. p. 16-28.

7. Drogovoz P.A., Sadovskaya T.G., Chursin A.A., Shiboldenkov V.A. Neural network analysis of the influence of sociocultural factors on the innovative activity of the state // Research and Development. Social and humanitarian research and technology. 2017.V.6. No. 2. p. $72-80$

8. Drogovoz P.A., Sadovskaya T.G., Chursin A.A., Shiboldenkov V.A. The use of selforganizing neural network maps for cross-cultural analysis // Scientific research and development. Modern communication science. 2017.V.6. No. 2. p. 8-15.

9. Drogovoz P.A., Sadovskaya T.G., Shiboldenkov V.A., Popovich A.L. Development of neural network tools for the intellectual analysis of economic indicators // Audit and financial analysis. 2015. No. 3. p. 431-440.

10. Rach D. V. The method of the mastered volume in the tasks of risk management in projects // Project Management and Production Development. 2011. no. 4 (40). p.1-12.

11. Problems of implementation and risk assessment of investment projects in the road sector / N, D Luskatov, O.V. Luskatova II University Herald (State University of Management), 2010. No. 8. - p. 101 - 105; Assessment of the impact of risk on the effectiveness of budget investments in the infrastructure of the Vladimir region / N.D. Luskatov, O.V. Luskatova // Theory and practice of service: economics, social sphere, technology, 2011. No. 3 (9), pp. 87 to 95; Innovative risks in budget investments in the road infrastructure of the Vladimir region / ND Luskatov, VG Chernov II Dynamics of complex systems, 2012, No. 1, t. 6., pp. $25-29$.

12. Furta S. D. On the problems of using the accrued volume method for analyzing project status // 21st Century Initiatives. 2009. no. 3, p. 38-43. 